\title{
Criopreserved ovarian tissue transplantation and bone restoration metabolism in castrated rats
}

\section{Transplante de tecido ovariano criopreservado e restauração do metabolismo ósseo em ratas castradas}

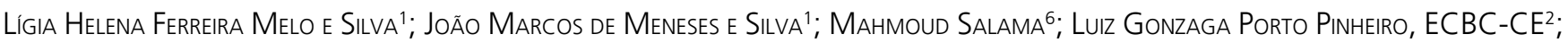
Franciele Osmarini lunardi; Paulo Goberlânio Barros da Silva ${ }^{1}$; Carlos Gustavo Hirth'; igor Freitas de lucena ${ }^{4}$; Glauco jorge da Costa Gomes5; josé Alberto Dias Leite ${ }^{1}$

\section{A B S T R A C T}

\begin{abstract}
Objectives: to evaluate estradiol levels and autotransplantation heated ovarian tissue effects, after vitrification, on rats bone metabolism previously oophorectomized bilaterally. Methods: experimental study with 27 rats aged 11 to 12 weeks and weighing 200g to 300g, submitted to bilateral oophorectomy and ovarian tissue cryopreservation for subsequent reimplantation. Animals were divided into two groups, $A$ and $B$, with 8 and 19 rats, respectively. Autotransplantation occurred in two periods according to castration time: after one week, in group $A$, and after one month in group $B$. Serum estradiol measurements and ovary and tibia histological analysis were performed before and after oophorectomy period (early or late) and one month after reimplantation. Results: in groups $A$ and $B$, tibia median cortical thickness was $0.463 \pm 0.14 \mathrm{~mm}($ mean $\pm S D)$ at the baseline, $0.360 \pm 0.14 \mathrm{~mm}$ after oophorectomy and $0.445 \pm 0.17 \mathrm{~mm}$ one month after reimplantation $p<0.005$ ). Trabecular means were $0.050 \pm 0.08 \mathrm{~mm}$ (mean $\pm S D$ ) at baseline, $0.022 \pm 0.08 \mathrm{~mm}$ after oophorectomy and $0.049 \pm 0.032 \mathrm{~mm}$ one month after replantation $(p<0.005)$. There was no statistical difference in estradiol variation between the two study groups ( $p=0.819$ ). Conclusion: cryopreserved ovarian tissue transplantation restored bone parameters, and these results suggest that ovarian reimplantation in women may have the same beneficial effects on bone metabolism.
\end{abstract}

Keywords: Menopause. Osteoporosis, Postmenopausal. Estrogens. Primary Ovarian Insufficiency. Tissue Transplantation. Cryopreservation.

\section{INTRODUCTION}

O varian aging and cytotoxic treatments are the most common causes to women fertility loss. According to recent reports, 700.000 women in the United States and 300.000 women in Brazil are diagnosed with cancer each year. Approximately $8 \%$ of these women are under 40 years of age and are at risk for fertility loss after aggressive gonadotoxic anticancer treatments. Many strategies were developed to prevent fertility loss in young women and girls undergoing these treatments, which significantly increase survival rates for most cancers ${ }^{1}$. Several options are available, such as cryopreservation of embryos, oocytes and ovarian tissue, and ovarian tissue autotransplantation ${ }^{2-5}$.
According to recent publications, cryopreservation and ovarian tissue autotransplantation can be used to restore fertility in cancer patients, in patients who do not respond adequately to conventional treatments and in those with premature ovarian failure ${ }^{6,7}$. Although experimental, cryopreservation and ovarian tissue autotransplantation resulted in more than 86 healthy babies birth all over the world ${ }^{8}$ with approximately $25 \%$ live birth rate per transplantation ${ }^{5}$.

One of the consequences of natural or induced ovarian failure is osteoporosis, characterized by bone mass and mineral density loss, thus increasing fractures risk. Osteoporosis is an important complication of old age in women and is strongly associated with sex hormones deficiency, but it can also be caused by alcoholism or

1 - Federal University of Ceará, Fortaleza, CE, Brazil. 2 - Maternity School Assis Chateaubriand, Fortaleza, CE, Brazil. 3 - State University of Ceará, Fortaleza, CE, Brazil. 4 - School of Medicine Unichristus, Fortaleza, CE, Brazil. 5 - Hospital São Carlos, Fortaleza, CE, Brazil. 6 - Cologne University, Cologne - Germany. 
corticosteroids high doses treatment. ${ }^{9}$ In the United States, osteoporosis causes approximately two million fractures annually, including 547,000 vertebral fractures, 300,000 hip fractures and 135,000 pelvic fractures ${ }^{10,11}$.

To study agents capable of preserving bone metabolism and preventing osteoporosis, several animal models have been used. According to Food and Drug Administration (FDA) guidelines, bone metabolism studies based on rat models should include proximal tibia, distal femur or lumbar vertebrae evaluations ${ }^{12}$. Oophorectomized mouse provides an excellent preclinical animal model that accurately reveals human skeleton important clinical features under hypoestrogenism and can be used to evaluate responses to therapeutic agents ${ }^{13}$.

The specific development of osteopenia/ spongy osteoporosis site in oophorectomized rats is one of the most reproducible biological responses in skeletal research ${ }^{14}$. After oophorectomy, rapid loss of spongy bone mass and bone strength occurs, followed by a loss slower rate to reach, finally, a bone mass stable phase after 90 days. These bone loss characteristics mimic bone changes after oophorectomy or menopause in humans ${ }^{15}$.

Our study aim was to evaluate estradiol levels and heated ovarian tissue autotransplantation effects, after vitrification, on bone metabolism in rats previously oophorectomized bilaterally.

\section{METHODS}

This study included 27 Wistar rats (Rattus norvegicus) aged 11 to 12 weeks and weighing $200 \mathrm{~g}$ to $300 \mathrm{~g}$. In this period there was hormonal maturation and end of growth of distal tibial plate, that happens after three months of age ${ }^{14}$. Animals were housed in individual cages in a controlled environment (circadian cycle, $22 \pm 2^{\circ} \mathrm{C}$, constant humidity and food and water ad libitum). All experimental protocols were reviewed and approved by the Animal Research Ethics Committee of Federal University of Ceará, and filed under number 79/2012.

A double-blind experimental study was performed in adult rats. For an experimental model with $90 \%$ power for the test and 0.05 significance level, considering 0.2 (20\%) maximum deviation and $0.5(50) \%$ ) expected difference between groups (d), the sample calculation must be 4.36 animals, that is, five animals per group, rounded to next whole number. In our study, we used the minimum number of eight rats in group $A$, respecting this rule with safety margin. The animals were divided into two groups, $A$ and $B$, with eight and 19 rats, respectively.

Bilateral oophorectomy was performed and extracted ovaries were cryopreserved by vitrification. Vitrified ovaries were then reimplanted into oophorectomized rats, one week (group A) or one month (group B) after oophorectomy. Serum estradiol and tibia bone tissue histological analysis were performed prior to oophorectomy (baseline parameters), at the end of surgical castration period (surgical castration) and one month after transplantation (recovery parameters).

\section{Ovarian and bone tissue collection}

After two hours fasting (to reduce drugs amount needed), abdominal area trichotomy and antisepsis with Chlorhexidine solution was performed. The animals were anesthetized with ketamine/xylazine $(40 \mathrm{mg} / \mathrm{kg}$ or $5 \mathrm{mg} /$ $\mathrm{kg}$, respectively) intraperitoneal injection in the right lower abdominal quadrant, according to Federation of Associations of Laboratory Animal Science guidelines ${ }^{16}$. In full anesthetic effect, $10 \mathrm{ml}$ at $0.9 \%$ physiological saline for hydration effect was injected into the subcutaneous region of the animal's back. We proceeded then to laparotomy, with pelvic organs exposure and bilateral oophorectomy. The ovaries were dissected, in order to remove all the fat, and sliced in an approximate $2 \mathrm{~mm}$ size $\mathrm{s}^{3}$. One ovary was immediately submitted to histological analysis, while the other was cryopreserved by vitrification $(n=27)$. The abdominal wall was sutured with 5-0 nylon in two planes (peritoneum-aponeurotic planes and skin).

Then, bone tissue biopsy of the left posterior leg proximal tibia was also performed. For this, after antisepsis and trichotomy of rat left thigh inner part, a $1.5 \mathrm{~cm}$ incision in length was made removing easily the 
skin around the thigh. Once the deep musculature was exposed, it was set aside for bone exposure of the anterior proximal part, about $5 \mathrm{~mm}$ from the insertion of the tibia. The bone biopsy was performed with a $2 \mathrm{~mm}$ diameter helical drill coupled to a mini-drill (3i Implant Innovations Inc., Palm Beach Gardens, FL, USA), with 12,000rpm rotation and a constant irrigation with saline solution. The drill was positioned vertically and in perpendicular position to the bone longitudinal axis to penetrate the cortex, reaching the deep medullary canal, but without reaching contralateral side. Next, skin was sutured with 3-0 nylon at equidistant points.

On first postoperative day, acetaminophen $120 \mathrm{mg} / \mathrm{kg}$ and codeine $60 \mathrm{mg} / \mathrm{kg}$ were orally administered for analgesia.

\section{Ovarian tissue vitrification and heating}

Ovarian fragments vitrification and subsequent heating were carried out according to protocol described by Silva et al. ${ }^{17}$. In most cases, the ovaries were initially balanced in HEPES (2-[4-(2-hydroxyethyl)-piperazin-1-yl]ethanesulfonic acid) containing 10\% (v/v) ethylene glycol and $10 \%(\mathrm{v} / \mathrm{v})$ DMSO (dimethylsulfoxide) for 20 minutes at room temperature $\left(23^{\circ} \mathrm{C}\right.$ to $\left.26^{\circ} \mathrm{C}\right)$ and then immersed in vitrification solution containing $17 \%(\mathrm{v} / \mathrm{v})$ ethylene glycol, 17\% (v/v) DMSO and 0.75M sucrose in HEPES for three minutes. Ovaries were transferred individually with a minimal vitrification solution to a metal bucket surface floating in liquid nitrogen. Vitrified ovaries were stored in liquid nitrogen $\left(-196^{\circ} \mathrm{C}\right)$ for 30 to 60 minutes. Using refrigerated forceps, samples were placed in refrigerators containing liquid nitrogen.

To thaw the ovarian cortex, cryotubes were removed from Dewar vessel and maintained at room temperature for two minutes, followed by immersion in a $37^{\circ} \mathrm{C}$ water bath for two minutes. A slight and gentle stirring was carried out. Cryotubes contents were rapidly emptied into culture plates with Leibovitz L-15 medium, and washed three times with fresh medium to remove residual cryoprotectant prior to replantation, according to a protocol adapted from Lunardi et al. ${ }^{18}$. Each sample was subjected to a three to five minutes bath in solutions containing minimal essential medium plus $10 \%$ fetal calf serum and decreasing concentrations of sucrose $(0.5 \mathrm{M}$, $0.25 \mathrm{M}$ and $0.0 \mathrm{M}$ )

\section{Ovarian tissue autotransplantation}

To compare surgical castration early and late effects, rats randomly divided into groups $A$ and $B$, underwent vitrified ovarian tissue autotransplantation, performed at the greater omentum, one week after bilateral oophorectomy in group $A(n=8)$ and one month after bilateral oophorectomy in group $B(n=19)$. One month after ovarian autotransplantation in both groups (A and B), abdominal cavity was opened and transplanted ovaries were identified, evaluated macroscopically and removed. The animals were then submitted to euthanasia with lethal doses of previously used anesthetic.

\section{Estradiol Determination}

Serum estradiol level was measured in both groups in several moments: before bilateral oophorectomy (basal level), immediately before autotransplantation (surgical castration) and one month after autotransplantation (reimplantation). According to our laboratory protocol, $2 \mathrm{ml}$ of blood were taken from retro-orbital plexus using a heparinized capillary hematocrit tube. After blood centrifugation at 2500rpm for 15 minutes, plasma was collected and stored in a freezer for later use in hormonal assay. Enzymatic immunoabsorption assay kits (Diagnostics Biochem Canada Inc., assay sensitivity, $10 \mathrm{ng} / \mathrm{ml}$ ) were used to quantitatively measure serum estrogen levels.

\section{Tibias histological analysis}

In both groups, tibial biopsies were collected before bilateral oophorectomy (baseline), immediately before autotransplantation (surgical castration) and one month after autotransplantation (reimplantation). Tibia biopsy samples were fixed in $10 \%$ neutral 
buffered formaldehyde and decalcified in EDTA solution (ethylenediamine tetraacetic acid) for two weeks. After decalcification, specimens were subjected to routine histological processing and paraffin incorporation. Subsequently, $5 \mu \mathrm{m}$ paraffin sections from tibia metaphysis were dewaxed and stained with hematoxylin and eosin for optical microscopy examination ${ }^{19}$. Trabecular and cortical thickness, Havers channel diameter, osteoclast and osteoblast counts and the presence of osteoid were evaluated.

The methodology used was: a) trabecular thickness, cortical thickness and Havers channels diameter direct measurements using microscope and millimetric rule; b) Osteoblast and osteoclast count in Neubauer chamber $30 \times 70 \mathrm{~mm}$ and $4 \mathrm{~mm}$ thickness using zig-zag technique; c) Simple detection of osteoid presence or absence.

\section{Ovaries histological analysis}

In both groups, ovarian samples were submitted to histological analysis immediately after oophorectomy and immediately after euthanasia, to evaluate histological changes in ovaries captured with transplanted vitrification. Ovarian tissue samples were fixed in 10\% paraformaldehyde and incorporated in paraffin. The $8 \mu \mathrm{m}$ sections were prepared for staining with hematoxylin and eosin. The sections were analyzed under a light microscope coupled to an image acquisition system (LAZ 3.5, LEICA - DM1000 models). Qualitative follicle and histological evaluations were performed using conventional classifications ${ }^{20}$.

To carry out this protocol, morphometry and histometry following parameters were used: a) Follicles number count per sample, through normal primordial follicles quantification, defined as those that had a welldefined cavity containing an oocyte with a nucleus and atretic primordial follicles quantification, that is, those that presented granulosa cells in degenerative process and, often, with apparent oocyte degeneration, with eosinophilic ooplasm, contraction and chromatin clumps formation or wrinkled nuclear membrane; b) Presence or not of corpus luteum (CL).

\section{Statistical analysis}

Statistical analyzes were blind and performed by specialists. Findings were analyzed using ANOVA and t-tests of paired samples. Degrees of freedom and statistical significance level were defined in $n-1$ and $5 \%(p<0.05)$, respectively. Rosner ${ }^{21}$ table was used for reference. Study variables were dichotomous (presence/absence). Data were analyzed with Fisher exact test, using GraphPad Prism 5.0 and expressed as absolute frequencies and percentages. Statistical significance level was established at $5 \%(p<0.05)$. For all the variables studied, each animal was its control, to avoid possible errors with previous diseases in the animal. Therefore, samples were taken before starting the procedures.

\section{RESULTS}

\section{Plasma estradiol level}

There was no statistically significant difference between estradiol levels variation in the two study groups ( $p=0.819)$. In animals with early menopause, despite the variation between baseline levels $(25.6 \pm 0.8 \mathrm{ng} / \mathrm{dL})$ and those of the immediate postoperative period $(19.0 \pm 1.1 \mathrm{ng} /$ $\mathrm{dL}$ ) and those of the one-month postoperative period $(25.6 \pm 3.9 \mathrm{ng} / \mathrm{dL})$, there was no significant difference between the three estradiol analysis moments $(p=0.140)$. The late menopausal group, however, presented a significant reduction in estradiol levels between the preoperative period $(28.0 \pm 1.1 \mathrm{ng} / \mathrm{dL})$ and the immediate postoperative period $(19.7 \pm 1.6 \mathrm{ng} / \mathrm{dL})$, with recovery of normal levels one month after surgery $(25.8 \pm 0.5 \mathrm{ng} / \mathrm{dL})$ $(p=0.001)$.

\section{Ovarian graft}

In $81.5 \%$ of animals (group $A: n=7 / 8,87 \%$, group B: $n=15 / 19,78.9 \%, p=0.080)$, the graft was successful 
(presence of follicles). In general, approximately $40.7 \%$ of grafts presented atheromatous follicles, $27.3 \%$ exhibited atretic and primordial follicles and $13.5 \%$ presented primordial follicles and corpus luteum. No ovarian graft was found in remaining 18.3\%: only inflammatory and scar tissue and/or fibrosis were found in these animals.

\section{Bone parameters}

\section{Cortical bone}

In general, tibia average cortical thickness was $0.463 \pm 0.14 \mathrm{~mm}$ at the baseline, $0.354 \pm 0.14 \mathrm{~mm}$ after the oophorectomy, and $0.446 \pm 0.17 \mathrm{~mm}$ in the month following ovarian autotransplantation $(p<0.005)$ (Figure 1). Paired t test, adopting as a degree of freedom the value ( $n-1)$ and taking as " $p$ " (probability) 0.005 value, receives 2,977 value. As in our calculations we found 5.28 value, we conclude that $p<0.005$.
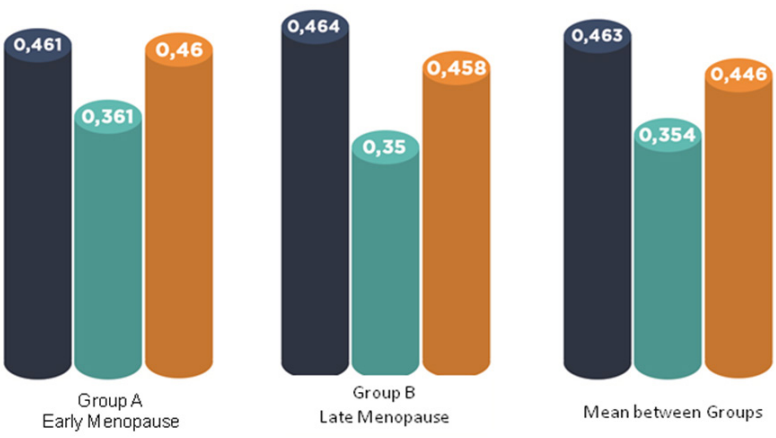

Baseline Levels

\section{Post-oophorectomy}

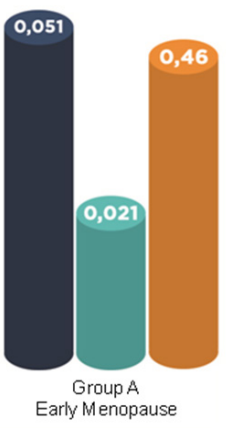

Baseline Levels

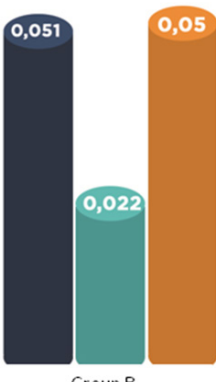

Late Menopause

Post-oophorectomy

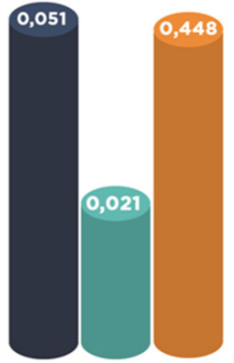

Mean between Groups

Post-reimplantation

Figure 2. Tibia trabecular thickness $(\mathrm{mm})(\mathrm{p}<0.005)$. Blue: basal; Green: castration; Orange: reimplantation.

In cortical bone, before oophorectomy, during metaphyseal-diaphysis transition we observed soft tissue and bone, osteoblasts and osteocytes borders in compact spaces. Osteoblasts border was absent in group A, one week after oophorectomy. One month after autotransplantation, there was absence of trabeculae (Figure 3). In group B, 30 days after oophorectomy, we observed extensive, occasionally empty channels (without osteocytes) and osteoblast foci. However, one month after ovarian autotransplantation, we observed cortical bone formation containing a border of osteoblasts, channels and large gaps containing osteocytes (Figure 4). We found an osteoblasts border and hematopoietic matrix in trabecular bone before oophorectomy.
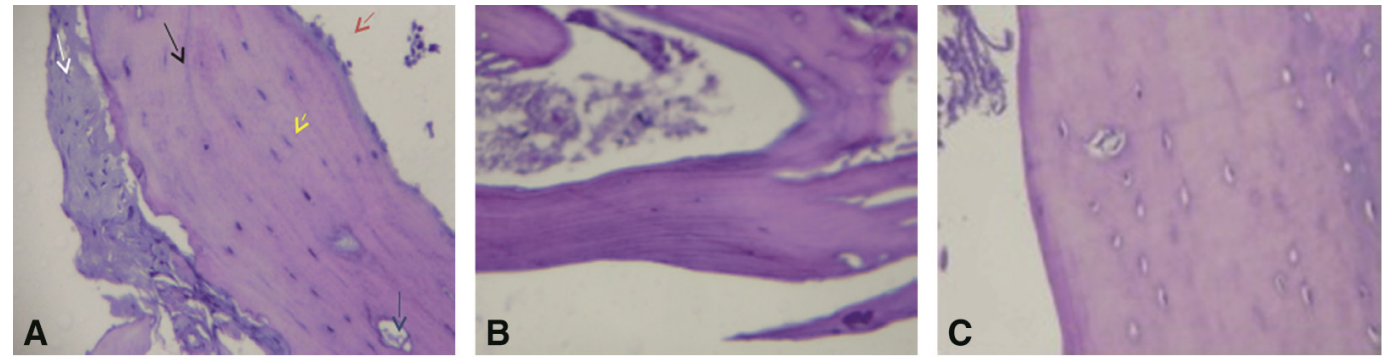

Figure 3. Cortical bone histology (HE 100x)- Group A

A) Basal; B) Post-oophorectomy; C) Post-reimplantation. 

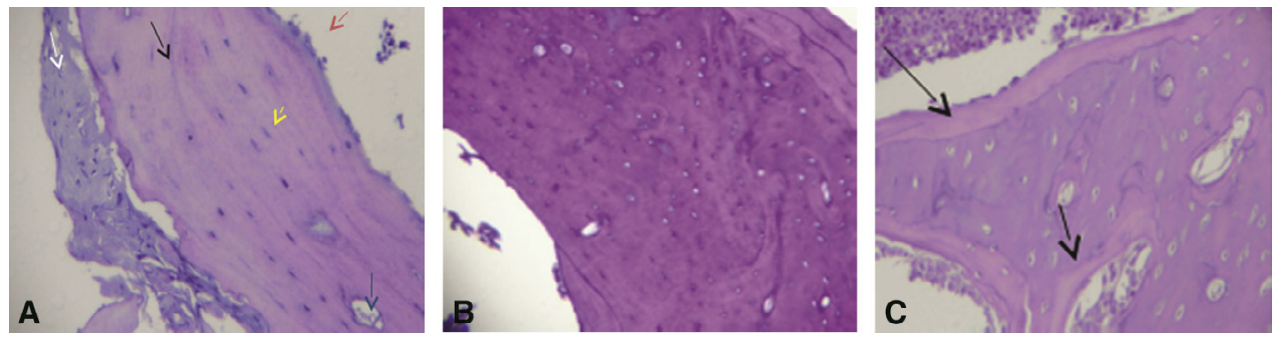

Figure 4. Cortical bone histology (HE 100x)- Group B.

A) Basal; B) Post-oophorectomy; C) Post-reimplantation.

Subsequently, group A demonstrated trabecula irregularity, one week after oophorectomy. We observed a hematopoietic matrix one month after ovarian autotransplantation (Figure 5). In group B, one month after oophorectomy, we observed extensive channels and gaps occasionally empty (i.e., without osteocytes) and osteoblasts foci. However, one month after ovarian autotransplantation, we observed trabecular bone formation containing osteoblasts border, channels and large gaps containing osteocytes (Figure 6).

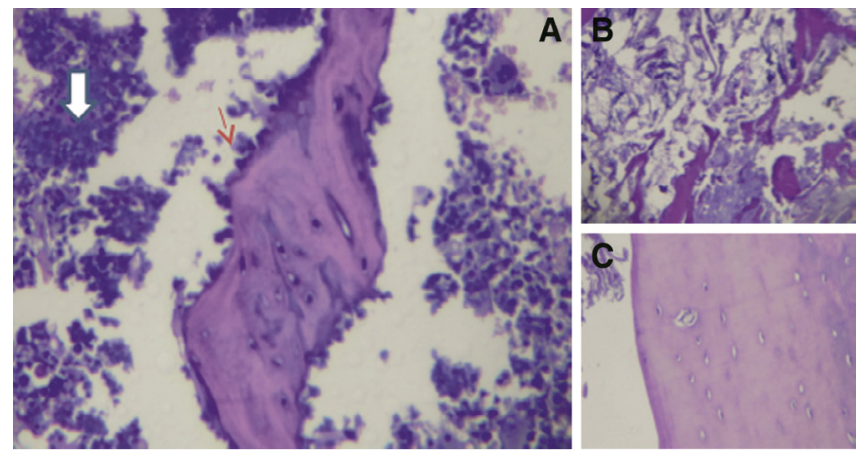

Figure 5. Trabecular bone histology (HE 100x)- Group A. A) Basal; B) Post-oophorectomy; C) Post-reimplantation.
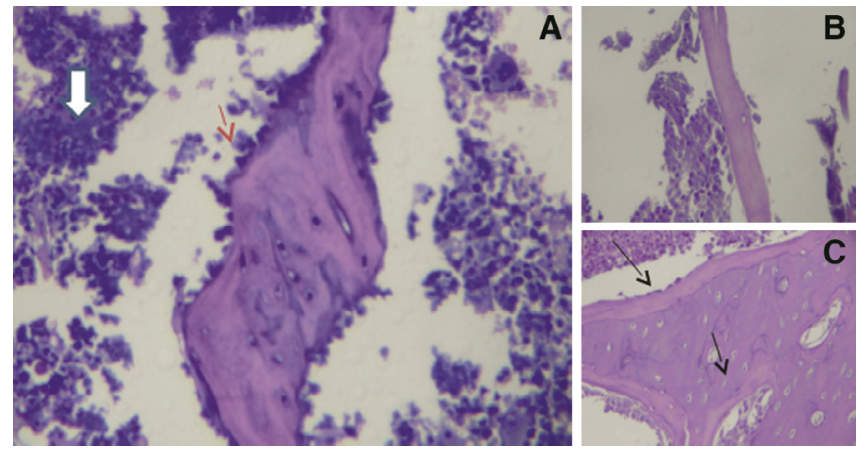

Figure 6. Trabecular bone histology (HE 100x)- Group B. A) Basal; B) Post-oophorectomy; C) Post-reimplantation.

When comparing transplant time, group A presented slightly improved cortical thickness, trabecular thickness and osteoblast counts, but these changes were not significant ( $p>0.05)$.

\section{DISCUSSION}

Ovarian tissue cryopreservation and autotransplantation in young women with cancer can prevent or reduce early osteoporosis and premature ovarian failure induced by gonadotoxic drugs. Using the terms "cryopreservation", "bone health", "menopause" and "bone metabolism" in research in PubMed, Lilacs and Cochrane database, we did not found published studies on cryopreserved ovarian tissue autotransplantation effects in bone metabolism. The studies with animal models for osteopenia and osteoporosis, show that, in models of oophorectomized rats, bone loss is gradual and irreversible, being clearly measurable from the first weeks ${ }^{14}$.

In this study, rats were oophorectomized bilaterally and their ovaries were cryopreserved via vitrification. Bone and tibial tissue biopsy samples were analyzed one week (group A) or one month (group B) after ovarian autotransplantation. Graft was successful in most rats. In both groups, compared to baseline levels, post-autotransplantation ovarian estradiol levels increased in almost half of the animals, suggesting successful transplantation and endocrine ovarian function recovery. In addition, average bones cortical thickness one month after ovarian autotransplantation was similar to that at baseline. In addition, bones cortical thickness at baseline was similar to the month after ovarian autotransplantation.

Histological analysis showed that, in general, bone quality measurements worsened after 
bilateral oophorectomy and improved after ovarian autotransplantation, suggesting that ovarian tissue grafts had effect on bone metabolism. This effect was evident for cortical thickness, trabecular thickness and osteoblast count. However, no alterations were observed in osteoids deposition. There was significant improvement in cortical and trabecular thickness.

These results demonstrate that oophorectomy and consequent decrease in ovaries estradiol production have a potential role in reducing osseous parameters values in these animals. After ovaries re-implantation with vitrified heating, we observed sexual hormone production restoration (estrogen) in these animals. Hormonal production restoration, in turn, resulted in a significant improvement in bone parameters values of these animals. However, we were unable to accurately measure follicle-stimulating hormone levels (FSH) because the kits used were not sensitive enough to detect variations in FSH levels; thus, all the results were the same. Our findings suggest that cryopreserved ovarian tissue autotransplantation can restore hormonal function and normalize bone metabolism in rats.

Some studies have already provided changes evidence in bone metabolism after ovarian hormones loss due to oophorectomy. Although these studies clearly showed a direct relationship between hormone absence duration and decreased bone parameters, resulting in osteopenia and osteoporosis, they did not investigate hormonal effects on bone metabolism after cryopreserved ovaries reimplantation.

Menopause can represent up to $30 \%$ to $40 \%$ of a woman's life and produces sequelae such as postmenopausal demineralization (i.e., osteoporosis), cardiovascular diseases increased risk, cognitive deficiencies, quality of life and sexual desire loss ${ }^{22}$. These findings suggest that cryopreserved ovarian tissue autotransplantation can restore hormonal function and normalize bone metabolism in castrated rats. Bone quality is monitored clinically by measuring bone mineral density. However, additional information, especially histological parameters, are necessary to accurately determine bone fragility and susceptibility to fractures ${ }^{23}$.

Connection between sex hormones and bone metabolism is well documented. Therefore, postmenopausal osteoporosis is mainly attributable to increase in bone osteoclasts resorption associated with estrogen deficiency. Estrogen-deficient animal models and humans studies showed reduced osteocytes viability in postmenopausal osteoporosis. As estrogen improves mature osteoclasts apoptosis, osteoclasts life is prolonged as estrogen levels decrease ${ }^{23}$. Estrogen showed doubling or tripling osteoclast apoptosis rate in vitro and in vivo $^{24}$. In direct contrast to its pro-apoptotic effect on osteoclasts, estrogen exerts an antiapoptotic effect on osteocytes. In other words, estrogen loss compromises osteocytes viability. In an immunohistochemical study that evaluated activated caspase-3 as an apoptosis marker in adult oophorectomized mice, estrogen loss increased osteocytes apoptosis, which is necessary to activate osteoclastic resorption ${ }^{25}$.

Traditionally, symptoms related to menopause were treated with hormone therapy $(\mathrm{HT})$. However, the publication of Women's Health Initiative (WHI) report in California, in 2002, indicated an association between $\mathrm{HT}$ and an increased breast cancer risk, which convinced many women to interrupt or reduce $\mathrm{TH}$ posology. Although several authors have subsequently shown that TH does not significantly increase breast cancer risk and cardiovascular disease, confidence in $\mathrm{TH}$ has not been fully restored. When $\mathrm{HT}$ is limited to menopause transition period (4 to 5 years), it often simply delays the onset of symptoms ${ }^{26}$. Therefore, prolonged menopause women (for example, 30 years) are susceptible to feel symptoms independently of therapy ${ }^{22}$.

Recently, Satpathy et al. ${ }^{27}$ described what they believed to be an osteoporosis epidemic and called for new strategies for osteoporosis long-term prevention. Ten years earlier, a meta-analysis found a $27 \%$ overall reduction in vertebral fractures among estrogen users. In addition, WHI estrogen-progestin study (2002) reported $33 \%, 29 \%, 35 \%$ and $24 \%$ reductions in the incidence of hip, arm/pulse, vertebral and total fractures, respectively, among women, assigned to estrogen plus progestin compared to those attributed to placebo during 5.6 years evaluation period. However, despite exogenous hormonal therapy temporary efficacy, cryopreservation and ovarian tissue autotransplantation are gaining ground as an alternative method to delay menopause ${ }^{28}$.

Ovarian tissue cryopreservation was developed more than two decades ago. This technique preserves the 
large endogenous reserve of ovarian follicles that would otherwise pass through atresia and is now used for fertility preservation for women facing gonadotoxic, potentially sterilizing treatments and can also be used to postpone menopause ${ }^{27,29}$. A technological developments review in cryopreservation and storage techniques for ovarian tissue has recently been published ${ }^{30}$. Ovarian tissue can be cryopreserved when the woman is still young, and then transplanted, after menopause, to restore ovarian functions ${ }^{28}$.

Ovaries of a newborn girl contain approximately two million follicles, present in resting follicles. This follicle store protects fertility and menstrual cycles from puberty to menopause. Regardless of age, a series of resting follicles are continually stimulated to grow, but only one follicle is selected for ovulation during each cycle ${ }^{29}$. On average, women ovulate approximately 400 to 500 times from puberty to menopause, and as a result, $99.9 \%$ of follicles degenerate. Many of these "wasted follicles" have development capacity (for sex steroids secretion), but they cannot contain oocytes suitable for reproduction ${ }^{31}$. As demonstrated by assisted reproduction, these follicles can be saved from degeneration and continue to grow and secrete sexual hormones ${ }^{32}$.

In addition, fertility does not decrease significantly with an ovary loss. A woman with an ovary will produce approximately $20 \%$ fewer mature oocytes compared to a woman with both ovaries after ovarian stimulation, indicating that follicle atresia in remaining ovary is reduced and more follicles survive pre-ovulatory stage $^{33}$. In healthy women, an ovary loss advances menopause onset age for only one year due to the huge follicles excess. In other words, normal women experience little or no effect on fertility or menopause onset age after ovarian tissue removal when young.

We can conclude with our study that cryopreservation and ovarian tissue autotransplantation help bone quality improvement in castrated rats. Despite expressive variation in hormone levels in groups subjected to different periods of surgical castration, there was no statistically significant difference between estradiol levels variation. There is bone histological effects reversal derived from estradiol deprivation after cryopreserved ovarian tissue autotransplantation.

\title{
R E S U M O
}

\begin{abstract}
Objetivos: avaliar os níveis de estradiol e os efeitos do autotransplante de tecido ovariano aquecido, após vitrificação, no metabolismo ósseo de ratas previamente ooforectomizadas bilateralmente. Métodos: trabalho experimental com 27 ratas com idades entre 11 e 12 semanas e pesando $200 \mathrm{~g}$ a $300 \mathrm{~g}$, submetidas à ooforectomia bilateral e criopreservação de tecido ovariano para posterior reimplante. Os animais foram divididos em dois grupos, A e B, com oito e 19 ratas, respectivamente. O autotransplante ocorreu em dois períodos de acordo com o tempo de castração: após uma semana, no grupo A, e após um mês no grupo B. Mensurações de estradiol sérico e análise histológica de ovário e tíbia foram feitos antes e após o período de ooforectomia (precoce ou tardio) e um mês após o

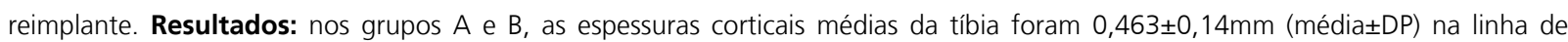
base, $0,360 \pm 0,14 \mathrm{~mm}$ após ooforectomia e $0,445 \pm 0,17 \mathrm{~mm}$ em um mês após o reimplante $(p<0,005)$. As médias trabeculares foram

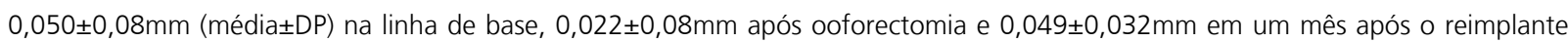
$(p<0,005)$. Não houve diferença estatística entre a variação do estradiol entre os dois grupos de estudo $(p=0,819)$. Conclusão: o transplante de tecido ovariano criopreservado restabeleceu os parâmetros ósseos, e estes resultados sugerem que a reimplantação ovariana em mulheres pode apresentar os mesmos efeitos benéficos sobre o metabolismo ósseo.
\end{abstract}

Descritores: Menopausa. Osteoporose Pós-Menopausa. Estrogênios. Insuficiência Ovariana Primária.

\section{REFERENCES}

1. Romao RL, Lorenzo AJ. Fertility preservation options for children and adolescents with cancer. Can Urol Assoc J. 2017;11(1-2Suppl1):S97-S102.

2. Loren AW, Mangu PB, Beck LN, Brennan L, Magdalinski
AJ, Partridge AH, Quinn G, Wallace WH, Oktay K; American Society of Clinical Oncology. Fertility preservation for patients with cancer: American Society of Clinical Oncology clinical practice guideline update. J Clin Oncol. 2013;31(19):2500-10.

3. Koch J, Ledger W. Ovarian stimulation protocols 
for onco-fertility patients. J Assist Reprod Genet. 2013;30(2):203-6.

4. Bortoletto P, Confino R, Smith BM, Woodruff TK, Pavone ME. Practices and attitudes regarding women undergoing fertility preservation: a survey of the National Physicians Cooperative. J Adolesc Young Adult Oncol. 2017;6(3):444-9.

5. Salama M, Winkler K, Murach KF, Seeber B, Ziehr SC, Wildt $L$. Female fertility loss and preservation: threats and opportunities. Ann Oncol. 2013;24(3):598-608.

6. Kawamura K, Cheng Y, Sun YP, Zhai J, Diaz-Garcia C, Simon C, et al. Ovary transplantation: to activate or not to activate. Hum Reprod. 2015;30(11):2457-60.

7. Donnez J, Dolmans MM. Ovarian cortex transplantation: 60 reported live births brings the success and worldwide expansion of the technique towards routine clinical practice. J Assist Reprod Genet. 2015;32(8):1167-70.

8. Jensen AK, Macklon KT, Fedder J, Ernst E, Humaidan $P$, Andersen CY. 86 successful births and 9 ongoing pregnancies worldwide in women transplanted with frozen-thawed ovarian tissue: focus on birth and perinatal outcome in 40 of these children. J Assist Reprod Genet. 2017;34(3):325-36. Erratum in: J Assist Reprod Genet. 2017;34(3):337.

9. Anderson RA, Cameron DA. Pretreatment serum antimüllerian hormone predicts long-term ovarian function and bone mass after chemotherapy for early breast cancer. J Clin Endocrinol Metab. 2011;96(5):1336-43.

10. Hsu WL, Chen CY, Tsauo JY, Yang RS. Balance control in elderly people with osteoporosis. J Formos Med Assoc. 2014;113(6):334-9.

11. Xiong Q, Tang P, Gao Y, Zhang L, Ge W. Proteomic analysis of estrogen-mediated signal transduction in osteoclasts formation. Biomed Res Int. 2015;2015:596789.

12. Thompson DD, Simmons HA, Pirie CM, Ke HZ. FDA Guidelines and animal models for osteoporosis. Bone. 1995;17(4 Suppl):125S-33S.

13. Lane NE, Haupt D, Kimmel DB, Modin G, Kinney $\mathrm{JH}$. Early estrogen replacement therapy reverses the rapid loss of trabecular bone volume and prevents further deterioration of connectivity in the rat. J Bone Miner Res. 1999;14(2):206-14.

14. Jee WS, Yao W. Overview: animal models of osteopenia and osteoporosis. J Musculoskelet Neuronal Interact. 2001;1(3):193-207.

15. Kalu DN. The ovariectomized rat model of postmenopausal bone loss. Bone Miner. 1991;15(3):175-91.

16. Guillen J. FELASA guidelines and recommendations. J Am Assoc Lab Anim Sci. 2012;51(3):311-21.

17. Silva JM, Pinheiro LG, Leite JA, Melo LH, Lunardi FO, Barbosa Filho RC, et al. Histological study of rat ovaries cryopreserved by vitrification or slow freezing and reimplanted in the early or late postmenopausal stage. Acta Cir Bras. 2014;29(5):299-305.

18. Lunardi FO, Chaves RN, de Lima LF, Araújo VR, Brito $I R$, Souza $C E$, et al. Vitrified sheep isolated secondary follicles are able to grow and form antrum after a short period of in vitro culture. Cell Tissue Res. 2015;362(1):241-51.

19. Malluche HH, Faugere MC. Atlas of Mineralized Bone Histology. $1^{\text {st }}$ ed. Basel: Karger; 1986.

20. Bancroft JD, Gamble, editors. Theory and practice of histological techniques. 6th ed. Philadelphia (PA): Elsevier, Churchill Livingstone; 2008.

21. Rosner B. Fundamentals of Biostatistics. 7th ed. Boston: Brooks/ Cole Engage Learning; 2010.

22. Lobo RA, Davis SR, De Villiers TJ, Gompel A, Henderson VW, Hodis HN, et al. Prevention of diseases after menopause. Climacteric. 2014;17(5):540-56.

23. McCreadie BR, Goldstein SA. Biomechanics of fracture: is bone mineral density sufficient to assess risk? J Bone Miner Res. 2000;15(12):2305-8.

24. Parfitt AM, Mundy GR, Roodman GD, Hughes DE, Boyce BF. A new model for the regulation of bone resorption, with particular reference to the effects of bisphosphonates. J Bone Miner Res. 1996;11(2):1509.

25. Hughes DE, Dai A, Tiffee JC, Li HH, Mundy GR, Boyce BF. Estrogen promotes apoptosis of murine osteoclasts mediated by TGF-beta. Nat Med. 1996;2(10):1132-6.

26. Emerton KB, Hu B, Woo AA, Sinofsky A, Hernandez C, Majeska RJ, et al. Osteocyte apoptosis and control of bone resorption following ovariectomy in mice. Bone. 2010;46(3):577-83.

27. Satpathy S, Patra A, Ahirwar B. Experimental techniques for screening of antiosteoporotic activity 
in postmenopausal osteoporosis. J Complement Integr Med. 2015;12(4):251-66.

28. Andersen $C Y$, Kristensen SG. Novel use of the ovarian follicular pool to postpone menopause and delay osteoporosis. Reprod Biomed Online. 2015; 31(2):128-31.

29. Hovatta O, Silye R, Abir R, Krausz T, Winston RM. Extracellular matrix improves survival of both stored and fresh human primordial and primary ovarian follicles in long-term culture. Hum Reprod. 1997;12(5):1032-6.

30. Rodriguez-Wallberg KA, Oktay K. Recent advances in oocyte and ovarian tissue cryopreservation and transplantation. Best Pract Res Clin Obstet Gynaecol. 2012;26(3):391-405.

31. Gosden RG. Low temperature storage and grafting of human ovarian tissue. Mol Cell Endocrinol. 2000;163(1-2):125-9.

32. Behre HM, Howles CM, Longobardi S; PERSIST Study Investigators. Randomized trial comparing luteinizing hormone supplementation timing strategies in older women undergoing ovarian stimulation. Reprod Biomed Online. 2015;31(3):339-46.

33. Pelosi E, Simonsick E, Forabosco A, Garcia-Ortiz JE, Schlessinger $D$. Dynamics of the ovarian reserve and impact of genetic and epidemiological factors on age of menopause. Biol Reprod. 2015;92(5):130.

Received in: 30/10/2017

Accepted for publication: 30/11/2017

Conflict of interest: none.

Source of funding: none.

\section{Mailing address:}

Lígia Helena Ferreira Melo e Silva

E-mail: draligiahelena@hotmail.com / drjoaomarcosmeneses@hotmail.com

\section{(cc) BY}

